\title{
ANALISA DAN PERANCANGAN SISTEM INFORMASI AKTIVA TETAP DALAM UPAYA PENGENDALIANAKTIVA TETAP YANG BERSUMBER DARI PEMBELIAN DAN DONASI
}

\author{
Eka Novianti \\ Jurusan Akuntansi, Fakultas Ekonomi dan Bisnis, Universitas Bina Nusantara \\ Jl. K.H. Syahdan No. 9, Palmerah, Jakarta Barat 11480 \\ eka1921@gmail.com
}

\begin{abstract}
In an institution of capital assets is one of the very important work that needs to be managed well, both in terms of maximizing the value of benefits and terms of existence that can be used optimally. Likewise, management information about the assets that will be used for good decision-making. A system designed to optimally utilize the information. Fixed Assets Information System that meets the user requirements and works properly can provide precise and accurate information is required. Users can easily find out the value of the acquisition and the value of accumulated depreciation of assets which no longer belongs to the company. The values that have an impact on the Financial Position Report will generate a report more accurate and reliable.
\end{abstract}

Keywords: fixed asset, information system

\begin{abstract}
ABSTRAK
Di dalam suatu institusi aktiva merupakan salah satu modal kerja yang sangat penting yang perlu dikelola dengan baik, baik dari sisi pemaksimalan nilai manfaatnya maupun dari sisi keberadaannya agar dapat digunakan secara optimal.Begitu juga pengelolaan informasi mengenai aktiva-aktiva tersebut agar dapat digunakan untuk pengambilan keputusan yang baik.Suatu sistem dibuat untuk dapat memanfaatkan informasi secara maksimal.Sistem Informasi Aktiva Tetap yang memenuhi User Requirements dan bekerja dengan baik dapat menyediakan informasi yang tepat dan akurat yang dibutuhkan.User dapat dengan mudah mengetahui nilai perolehan dan nilai akumulasi penyusutan setiap aktiva yang sudah tidak menjadi milik perusahaan. Nilai yang berdampak pada Laporan Posisi Keuangan ini akan menghasilkan laporan yang lebih akurat dan dapat dipercaya.
\end{abstract}

Kata kunci: aktiva tetap, sistem informasi 


\section{PENDAHULUAN}

Di dalam suatu institusi aktiva merupakan salah satu modal kerja yang sangat penting yang perlu dikelola dengan baik, baik dari sisi pemaksimalan nilai manfaatnya maupun dari sisi keberadaannya agar dapat digunakan secara optimal.Begitu juga pengelolaan informasi mengenai aktiva-aktiva tersebut agar dapat digunakan untuk pengambilan keputusan yang baik.Suatu sistem dibuat untuk dapat memanfaatkan informasi secara maksimal.

Adanya permintaan pembelian aktiva yang tidak dibutuhkan dapat menyebabkan penggunaan dana yang kurang maksimal. Dana yang seharusnya dapat digunakan untuk keperluan yang lain, digunakan untuk pembelian aktiva yang sebenarnya tidak dibutuhkan. Oleh karena itu, butuh adanya pencatatan aktiva yang akurat.

Selain itu, membayar tagihan barang yang tidak diterima menyebabkan pembengkakan pengeluaran.Untuk mengatasi hal ini, dibutuhkan adanya sistem informasi yang memadai untuk dapat membantu pengecekan antara tagihan dengan penerimaan barang.Dengan memiliki sistem yang terus menerus dikembangkan, dapat mengendalikan kesalahan yang mungkin terjadi.

Beberapa ancaman yang bisa saja terjadi dalam suatu aktifitas pengelolaan aktifa, dinataranya : sistem pengelolaan aktiva yang masih sederhana, data yang belum terintegrasi, dapat menyebabkan data tidak konsisten pada bagian yang satu terhadap bagian yang lainnya, sistem pencatatan masih manual yang memakan waktu pemrosesan yang cukup lama, kegiatan yang tidak dilaporkan atau data yang kurang lengkap akan berdampak pada pengambilan keputusan yang tidak tepat. Melihat adanya segalan ancaman tersebut, maka diperlukan suatu Sistem Informasi yang bekerja dengan baik yang dapat menyediakan informasi yang lengkap dan akurat, selain membantu mengatasi masalah-masalah tersebut, juga dapat digunakan sebagai dasar pengambilan suatu keputusan sangat diperlukan.

\section{METODE}

Objek dalam penelitian ini adalah salah satu perusahaan yang bergerak di industry fashion dengan kapasitas produksi besar.

Sumber data dari penelitian ini diperoleh dari dua sumber, yaitu: data primer yang diperoleh langsung dari sumbernya baik melalui metode wawancara maupun observasi secara langsung terhadap proses kegiatan yang sedang berlangsung / dilakukan tanpa mengubah system aplikasi yang sudah ada, dan data sekunder yang diperoleh dari pihak ketiga seperti buku-buku, literatur, dokumen-dokumen, dan hasil-hasil penelitian yang berhubungan dengan penelitian dan penyusunan makalah ini.

Teknik pengumpulan data yang digunakan oleh penulis adalah observasi dan dokumentasi, yaitu teknik pengumpulan data dengan cara mengamati masalah yang bersangkutan secara langsung dari data/dokumentasi yang ada.

\section{HASIL DAN PEMBAHASAN}

Dalam pengelolaan aktiva tetap melalui pemanfaatan suatu system informasi aktiva tetap yang berdiri sendiri, system informasi aktiva yang terintegrasi dalam suatu system informasi, maupun pencatatan manual, tetap harus berpatokan pada atuan-aturan keuangan yang berlaku terkait pengelolaan aktiva. 
Beberapa istilah yang diambil menurut PSAK No.16 tentang Aktiva Tetap tahun 2009, yaitu: (1) Aktiva Tetap adalah aktiva berwujud yang dimiliki untuk digunakan dalam produksi atau penyediaan barang atau jasa, untuk direntalkan kepada pihak lain, atau untuk tujuan administratif; dan diharapkan untuk digunakan selama lebih dari satu periode. (2) Biaya Perolehan adalah jumlah kas atau setara kas yang dibayarkan atau imbalan lain yang diserahkan untuk memperoleh suatu aktiva pada saat perolehan. (3) Jumlah yang dapat disusutkan adalah biaya perolehan suatu aktiva, atau jumlah lain yang menjadi penggantian biaya perolehan, dikurangi nilai residunya. (4) Nilai residuaktiva adalah jumlah yang diperkirakan akan diperoleh entitas saat ini dari pelepasan aktiva, setelah dikurangi taksiran biaya pelepasan, jika aktiva tersebut telah mencapai umur dan kondisi yang diharapkan pada akhir umur manfaatnya. (5) Penyusutan adalah alokasi sistematis jumlah yang dapat disusutkan dari suatu aktiva selama umur manfaatnya. (6) Umur manfaat adalah suatu periode dimana aktiva diharapkan akan digunakan oleh entitas.

\section{Metode FAST (Framework for the Application of System Thinking)}

FAST terdiri dari delapan fase berikut ini (Bentley, Whitten, \& Dittman, 2007): (1) Fase Scope Definition, dalam fase ini ditentukan ruang lingkup atau batasan-batasan proyek. Dengan menentukan ruang lingkup proyek, analis dapat menyediakan staf untuk tim proyek, memperkirakan anggaran pengembangan, dan menyiapkan jadwal untuk fase-fase yang lain. (2) Fase Problem Analysis, dalam fase ini kita mempelajari sistem yang ada dan menganalisa temuan-temuan untuk menyediakan tim proyek dengan pemahaman yang lebih mendalam akan masalah-masalah yang memicu proyek. (3) Fase Requirement Analysis, dalam fase ini analis mendekati para pengguna untuk mencari tahu apa yang mereka perlukan atau yang mereka inginkan dari sistem yang baru. (4) Fase Logical Design, dalam fase ini dilakukan penerjemahan persyaratan-persyaratan bisnis ke dalam model-model sistem. Model sistem merupakan gambar sebuah sistem yang mewakili kenyataan yang diinginkan. (5) Fase Decision Analysis, dalam fase ini dilakukan identifikasi terhadap solusi-solusi teknis, menganalisis solusi-solusi untuk kepraktisan, dan merekomendasikan calon sistem sebagai solusi untuk didesain. (6) Fase Physical Design \& Integration, dalam fase ini menentukan bagaimana teknologi akan digunakan dalam sistem yang baru. Physical Design merupakan penerjemahan persyaratan-persyaratan pengguna ke dalam model sistem yang mengilustrasikan implementasi teknis persyaratan-persyaratan pengguna tersebut. (7) Fase Construction \& Testing, fase ini bertujuan untuk membangun dan menguji sebuah sistem yang memenuhi persyaratan bisnis dan spesifikasi desain fisik, dan mengimplementasikan antarmuka-antarmuka antara sistem yang baru dengan sistem yang telah ada. (8) Fase Instalation \& Delivery, dalam fase ini dilakukan penginstalan sistem, para analis melatih para pengguna sistem, membuat user manual, mengkonversi file dan database yang ada menjadi database yang baru, dan melakukan pengujian sistem final.

Pada umumnya, suatu proses analisa perancangan system informasi akuntansi menggunakan metode FAST sebagai acuan dalam melakukan pengembangan sistem. Pada makalah ini hanya empat tahap pertama saja yang akan dibahas dengan gambaran metodologi seperti pada Gambar 1.

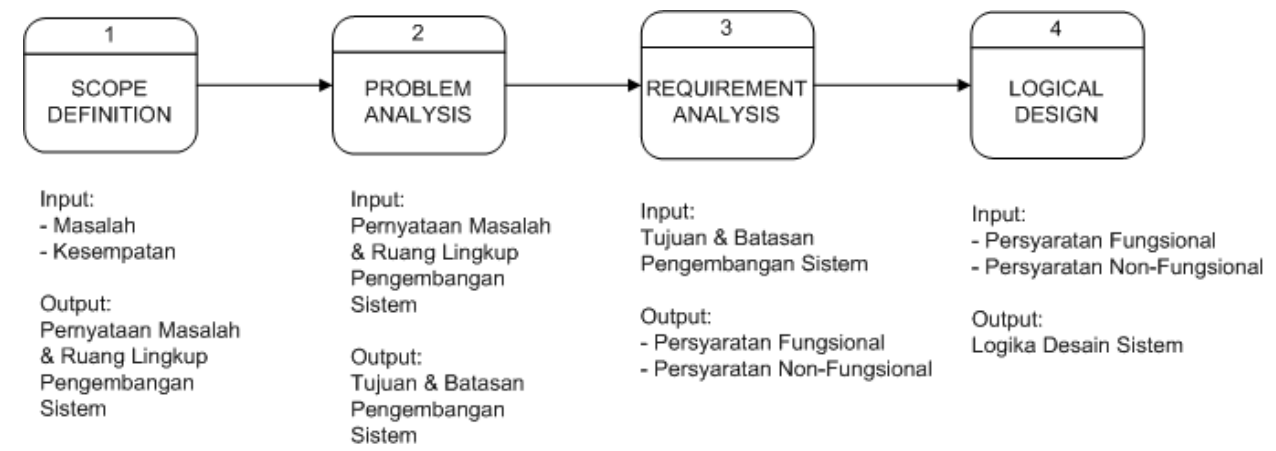

Gambar 1 Metodologi Penelitian 
Pada tahap pertama, akan diidentifikasi masalah-masalah dan kesempatan-kesempatan yang ada untuk dapat mengetahui ruang lingkup dari pengembangan sistem. Dari pernyataan masalah dan ruang lingkup tersebut akan masuk ke fase yang kedua yaitu menganalisis tujuan dan batasan-batasan sistem. Setelah ditentukan tujuan dan batasan dari sistem, kemudian masuk pada tahap yang ketiga untuk menganalisis persyaratan-persyaratan dari user.Persyaratan ini akan dikelompokkan menjadi persyaratan fungsional dan persyaratan non-fungsional. Setelah diketahui semua persyaratan user, kemudian masuk pada tahap yang terakhir yaitu merancang logika desain sistem.

\section{Scope Definition (Penentuan Ruang Lingkup)}

Pada tahap ini dilakukan pendefinisian lingkup pengembangan sistem, masalah, dan kesempatan yang ada. Permasalahan dan kesempatan yang ada akan lebih mudah dianalisa dengan cara dikategorikan berdasarkan kerangka PIECES Wetherbe, di antaranya seperti pada Tabel 1.

Tabel 1 Pernyataan Masalah

Pernyataaan Singkat Masalah dan Kesempatan Solusi yang Diusulkan

\section{Performance}

1. Semakin bertambahnya aktiva yang dimiliki menyebabkan dibutuhkan waktu berbulan-bulan untuk melakukan stok opname.

2. Waktu yang lama dalam menghitung nilai perolehan aktiva dan nilai akumulasi penyusutan aktiva.

3. Membutuhkan waktu yang lama untuk mengetahui kapan aktiva tersebut dibeli, berapa harga belinya, aktiva tersebut ditempatkan dimana, berapa jumlah aktiva yang dimiliki.

\section{Information and Data}

1. Kurangnya informasi yang diperlukan mengenai data supplier, pelelangan aktiva, penerimaan sumbangan, sumbangan keluar, dan perbaikan aktiva.

2. Informasi yang tidak akurat dalam hal pemindahan aktiva per ruangan.

3. Data tidak terintegrasi.

\section{Control}

1. Data dalam file aktiva tetap tidak konsisten.

2. Pengendalian untuk entry data ke dalam sistem masih lemah.

3. Tidak ada pengendalian terhadap pengolahan data oleh pihak yang tidak berwenang.

\section{Efficiency}

1. Pencatatan pergerakan formulir PP kurang efisien.

2. Pengkodean aktiva tidak efisien.

\section{Service}

1. Sistem tidak kompatibel dengan sistem-sistem yang lain.

2. Sistem menghasilkan informasi yang tidak akurat.

3. Sistem menghasilkan informasi yang tidak konsisten.
Penggunaan barcode.

Pengembangan sistem yang baru.

Pengembangan sistem yang baru.

Pengembangan sistem yang baru.

Pengembangan sistem yang baru yang mempermudah pelaporan.

Penggunaan database relational.

Penggunaan database relational. Pengembangan sistem baru yang sudah diberikan control untuk entry data. Pengembangan sistem yang baru dengan menambahkan user ID dan password setiap kali user akan masuk ke sistem.

Pengembangan sistem yang baru. Pengembangan sistem yang baru.

Pengembangan sistem yang baru. Pengembangan sistem yang baru. Pengembangan sistem yang baru. 


\section{Problem Analysis (Analisis Permasalahan)}

Dalam tahap ini akan dilakukan analisis lebih dalam mengenai masalah, kesempatan, tujuan dan batasan yang ada dengan menggunakan Tabel Matriks Masalah, Kesempatan, Tujuan, dan Batasan, diantaranya adalah seperti pada Tabel 2.

Tabel 2 Matriks Masalah, Kesempatan, Tujuan, dan Batasan

\begin{tabular}{|c|c|c|c|c|}
\hline \multicolumn{3}{|c|}{ Analisis Sebab Akibat } & \multicolumn{2}{|c|}{ Tujuan-tujuan Perbaikan Sistem } \\
\hline & $\begin{array}{l}\text { Masalah atau } \\
\text { Kesempatan }\end{array}$ & Sebab dan Akibat & Tujuan Sistem & Batasan Sistem \\
\hline \multicolumn{5}{|c|}{ Performance } \\
\hline 1. & $\begin{array}{l}\text { Membutuhkan waktu } \\
\text { yang lama untuk stok } \\
\text { opname. }\end{array}$ & $\begin{array}{l}\text { 1. Jumlah aktiva tetap } \\
\text { semakin banyak } \\
\text { tetapi jumlah } \\
\text { anggota tim yang } \\
\text { melakukan stok } \\
\text { opname tetap. }\end{array}$ & $\begin{array}{l}\text { 1. } \begin{array}{l}\text { Mengurangi } \\
\text { waktu stok } \\
\text { opname sebesar } \\
80 \% .\end{array} \\
\text { 2. Entry data lewat } \\
\text { keyboard } \\
\text { berkurang } 85 \% \text {. }\end{array}$ & $\begin{array}{l}\text { Sistem yang baru harus } \\
\text { dapat mengidentifikasi } \\
\text { barcode. }\end{array}$ \\
\hline \multicolumn{5}{|c|}{ Information and Data } \\
\hline 2. & $\begin{array}{l}\text { Informasi yang tidak } \\
\text { akurat dalam hal } \\
\text { pemindahan aktiva per } \\
\text { ruangan. }\end{array}$ & $\begin{array}{l}\text { Seringkali pemindahan } \\
\text { aktiva antar ruangan } \\
\text { tidak dilaporkan ke G\&A } \\
\text { Dept, sehingga data } \\
\text { aktiva tetap per ruangan } \\
\text { menjadi tidak akurat. }\end{array}$ & $\begin{array}{l}\text { Memberikan fasilitas } \\
\text { pelaporan } \\
\text { pemindahan aktiva } \\
\text { antar ruangan melalui } \\
\text { sistem. }\end{array}$ & $\begin{array}{l}\text { Sistem yang baru harus } \\
\text { sudah terintegrasi antar } \\
\text { bagian. }\end{array}$ \\
\hline \multicolumn{5}{|c|}{ Control } \\
\hline 3. & $\begin{array}{l}\text { Data dalam file aktiva } \\
\text { tetap tidak konsisten. }\end{array}$ & $\begin{array}{l}\text { File daftar aktiva belum } \\
\text { terintegrasi dengan Bag. } \\
\text { Keuangan sehingga jika } \\
\text { ada perubahan data, data } \\
\text { menjadi tidak konsisten. }\end{array}$ & $\begin{array}{l}\text { Menghasilkan data } \\
\text { yang sudah } \\
\text { terintegrasi sehingga } \\
\text { data akan selalu } \\
\text { konsisten. }\end{array}$ & $\begin{array}{l}\text { Sistem yang baru harus } \\
\text { menggunakan } \\
\text { pendekatan relational } \\
\text { database. }\end{array}$ \\
\hline \multicolumn{5}{|c|}{ Efficiency } \\
\hline 4. & $\begin{array}{l}\text { Pengkodean aktiva } \\
\text { tidak efisien. }\end{array}$ & $\begin{array}{l}\text { Pengkodean aktiva tetap } \\
\text { butuh waktu penomoran } \\
\text { yang harus } \\
\text { memperhatikan apakah } \\
\text { kode sudah benar, tidak } \\
\text { ada kode kembar, dan } \\
\text { kode sudah diurutkan. }\end{array}$ & $\begin{array}{l}\text { Menghasilkan } \\
\text { penomoran aktiva } \\
\text { berupa barcode. }\end{array}$ & $\begin{array}{l}\text { Sistem yang baru harus } \\
\text { dapat mengidentifikasi } \\
\text { barcode. }\end{array}$ \\
\hline \multicolumn{5}{|c|}{ Service } \\
\hline 5. & $\begin{array}{l}\text { Sistem tidak } \\
\text { kompatibel dengan } \\
\text { sistem-sistem yang } \\
\text { lain. }\end{array}$ & $\begin{array}{l}\text { Sistem masih berupa file- } \\
\text { file yang berdiri sendiri } \\
\text { sedangkan sistem yang } \\
\text { lain sudah menggunakan } \\
\text { pendekatan relational } \\
\text { database. }\end{array}$ & $\begin{array}{lr}\text { Menghasilkan } & \text { sistem } \\
\text { yang lebih } & \text { kompatibel dengan } \\
\text { kistem yang lain. }\end{array}$ & $\begin{array}{l}\text { Sistem yang baru harus } \\
\text { menggunakan } \\
\text { pendekatan relational } \\
\text { database. }\end{array}$ \\
\hline
\end{tabular}




\section{Requirement Analysis (Analisis Persyaratan)}

Dalam tahap ini, ditentukan persyaratan apa saja yang dibutuhkan oleh user. Persyaratan user akan dibagi menjadi dua, yaitu persyaratan fungsional, yaitu deskripsi mengenai aktivitas dan layanan yang harus diberikan/disediakan oleh sebuah system, dan persyaratan non-fungsional, yaitu deskripsi mengenai fitur, karakteristik, dan batasan lainnya yang menentukan apakah sistem memuaskan atau tidak.

Persyaratan fungsionalnya adalah: (1) sistem dapat memberikan hasil perhitungan nilai perolehan aktiva dan nilai akumulasi penyusutan aktiva yang cepat dan akurat; (2) sistem sudah terintegrasi antar bagian dengan menggunakan pendekatan relational database sehingga data tetap konsisten dan akurat; (3) sistem kompatibel dengan sistem-sistem yang lain; (4) sistem dapat mengidentifikasi barcode dan menghasilkan pengkodean aktiva berupa barcode; (5) sistem dapat memberikan informasi mengenai data supplier, aktiva tetap, karyawan, donatur, penerima donasi, unit, fakultas, ruangan, permintaan pembelian, purchase order, surat jalan, service aktiva, jenis aktiva; (6) sistem dapat menyimpan data mengenai proses-proses bisnis sebagai berikut: proses pengadaan aktiva yang meliputi pembuatan PP, pembuatan PO, dan penerimaan barang, proses perpindahan aktiva yang meliputi perpindahan aktiva dan peminjaman aktiva, proses pemusnahan aktiva yang meliputi pelelangan aktiva dan sumbang aktiva, proses pemeliharaan aktiva yang meliputi perbaikan aktiva, stok opname, dan penyusutan aktiva, dan pembuatan laporan-laporan untuk manajemen; (7) sistem memiliki pengendalian input, proses, dan output yang memadai.

Sementara itu, persyaratan non-fungsional adalah: (1) sistem mudah untuk dipelajari dan digunakan; (2) pelatihan kepada user yang memadai; (3) respon sistem yang cepat; (4) sistem menghasilkan informasi yang lengkap dan akurat; dan (5) sistem terbebas dari penggunaan data oleh pihak yang tidak berwenang.

Persyaratan-persyaratan tersebut di atas bersifat mandatory requirementyang harus dipenuhi oleh system.Tanpa persyaratan tersebut, sistem tidak ada gunanya.Mandatory requirement tidak dapat dirangking karena persyaratan ini sangat mendasar bagi semua solusi.Teknik yang digunakan dalam mengidentifikasi persyaratan user tersebut di atas adalah dengan melakukan wawancara kepada user yang bersangkutan, mengumpulkan fakta dari dokumentasi yang ada, dan observasi langsung ke lingkungan kerja.

\section{Logical Design (Perancangan Desain Logis)}

Pada tahap ini dilakukan perancangan sistem Aktiva Tetap dengan tujuan dapat meminimalisasi kelemahan-kelemahan yang saat ini dihadapi. Perancangan sistem yang akan dibuat terdiri atas pendokumentasian aktivitas dengan use case modeling, identifikasi alur data dan perancangan data flow diagram (DFD), identifikasi entitas dan perancangan entity relationship diagram (ERD) serta perancangan user interface.

Di tahap Identifikasi Business Actors Use-Case Requirement Modelling, dilakukan identifikasi terhadap actor yang terlibat dalam sistem informasi aktiva tetap perusahaan. Tahap ini termasuk: (1) karyawan adalah pihak yang mengajukan permohonan pembelian aktiva, peminjaman aktiva, pengajuan perpindahan aktiva, dan yang mengajukan laporan kerusakan aktiva; (2) kepala unit/kepala bagian adalah pihak yang menyetujui permohonan pembelian aktiva tingkat unit/bagian; (3) bagian pengadaan adalah pihak yang melakukan permintaan penawaran dari supplier, melakukan pembelian aktiva ke supplier, dan pengecekan spesifikasi barang dari supplier; (4) bagian keuangan adalah pihak yang melakukan penghitungan penyusutan aktiva; (5) security adalah pihak yang mengotorisasi keluar masuknya barang dari perusahaan; (6) supplier adalah pihak yang men-supply aktiva; (7) teknisi adalah pihak yang melakukan service aktiva; (8) donatur adalah pihak yang memberikan sumbangan aktiva perusahaan; (9) penerima donasi adalah pihak yang menerima sumbangan aktiva dari 
perusahaan; (10) manajemen adalah pihak yang menerima laporan-laporan pengelolaan aktiva untuk dapat dilakukan monitoring dan evaluasi sebagai dasar pengambilan keputusan.

Dalam Identifikasi Business Requirements Use Case, dapat kita lihat dalam use case context diagram yang memberikan gambaran mengenai tugas utama actor, informasi apa saja yang dibutuhkan actor dari sistem, informasi apa saja yang disediakan actor untuk sistem, perlu tidaknya sistem menginformasikan setiap perubahan atau kejadian yang terjadi kepada actor, dan perlu tidaknya actor menginformasikan setiap perubahan atau kejadian yang terjadi kepada sistem.

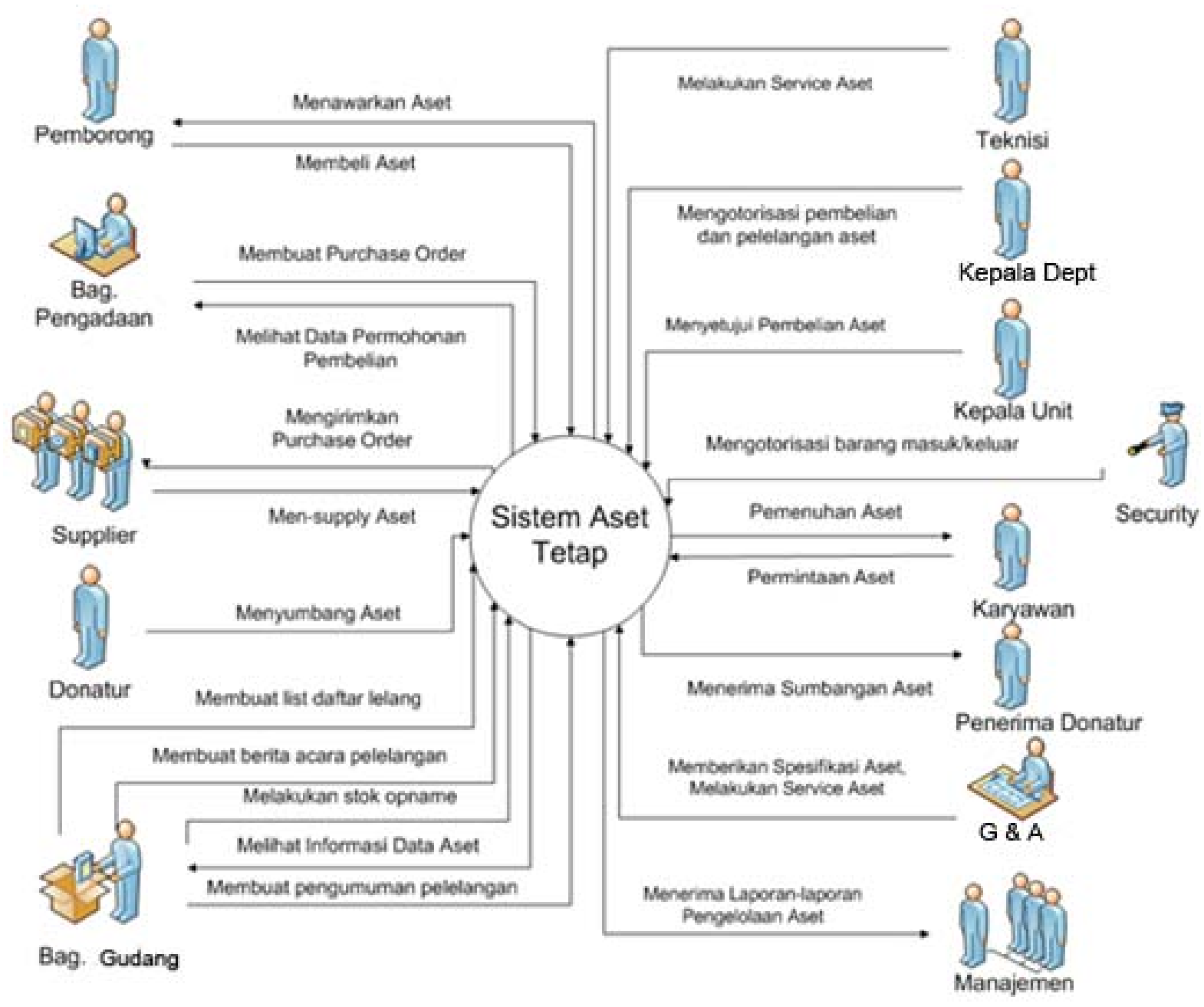

Gambar 2 Use Case Context Diagram

Use Case Narratives Documentation merupakan salah satu langkah yang seharusnya dilakukan pada saat implementasi suatu system mengingat bahwa pada formulir inilah prosedur transaksi yang berjalan dijelaskan. Satu use case narrative dari Sistem Informasi Aktiva Tetap seperti pada Tabel 3. 
Tabel 3 Use-Case Narrative

Author : John Doe

Project : : Sistem Informasi Aktiva Tetap

Date : :1July 2011

Version : 1.0

\begin{tabular}{|c|c|c|}
\hline Use-Case Name : & Buat Permohonan Pembelian & \multirow{4}{*}{$\begin{array}{l}\text { Use-Case Type } \\
\text { Business Requirements }: \sqrt{ }\end{array}$} \\
\hline Use-Case ID : & \multirow{2}{*}{$\begin{array}{l}\text { USE-CASE-000.00 } \\
\text { High }\end{array}$} & \\
\hline Priority : & & \\
\hline Source : & Requirement -001 & \\
\hline $\begin{array}{l}\text { Primary System } \\
\text { Actor : }\end{array}$ & \multicolumn{2}{|c|}{ Karyawan Unit/Bagian yang meminta pembelian barang. } \\
\hline $\begin{array}{l}\text { Other } \\
\text { Participating } \\
\text { Actors: }\end{array}$ & \multicolumn{2}{|c|}{$\begin{array}{l}\text { - Kepala Dept (pihak yang memberikan persetujuan pembelian) } \\
\text { - G\&A (pihak yang memberikan rekomendasi spesifikasi barang tertentu) } \\
\text { - Bag. Pengadaan (pihak yang menerima PP untuk dibuatkan PO) }\end{array}$} \\
\hline Description : & \multicolumn{2}{|c|}{$\begin{array}{l}\text { Use case ini menggambarkan karyawan unit membuat PP dengan diketahui } \\
\text { kepala unit/ untuk dimintakan persetujuan dari Kepala Dept. }\end{array}$} \\
\hline Precondition : & \multicolumn{2}{|c|}{-} \\
\hline Trigger: & \multicolumn{2}{|l|}{ Kebutuhan untuk membeli barang. } \\
\hline $\begin{array}{l}\text { Typical Course of } \\
\text { Events : }\end{array}$ & $\begin{array}{l}\text { Actor Action : } \\
\text { Step 1: Karyawan masuk ke menu } \\
\text { PP. } \\
\text { Step 3: Karyawan mengisi form PP } \\
\text { mengenai barang-barang yg akan } \\
\text { dibeli. } \\
\text { Step 6: Kepala bagian masuk ke } \\
\text { menu PP. } \\
\text { Step 8: Kepala bagian menyetujui } \\
\text { PP. }\end{array}$ & $\begin{array}{l}\text { System Response : } \\
\text { Step 2: Sistem menampilkan form } \\
\text { PP. } \\
\text { Step 4: Sistem melakukan validasi } \\
\text { atas input data oleh karyawan } \\
\text { kemudian update tabel PP. } \\
\text { Step 5: Sistem memberikan } \\
\text { notifikasi kepada kepala bagian dari } \\
\text { pemohon. }\end{array}$ \\
\hline Alternate Course: & \multicolumn{2}{|c|}{$\begin{array}{l}\text { Step 3: Untuk pembelian barang yang akan disumbangkan ke pihak lain, } \\
\text { maka centang kolom disumbangkan. } \\
\text { Step 6: Apabila kepala bagian tidak menyetujui sebagian atau keseluruhan } \\
\text { PP, sistem akan memberikan notifikasi ke karyawan. }\end{array}$} \\
\hline Conclusion : & \multicolumn{2}{|c|}{$\begin{array}{l}\text { Use case ini menyimpulkan apakah PP disetujui oleh Kepala Dept. atau } \\
\text { tidak. }\end{array}$} \\
\hline Postcondition: & \multicolumn{2}{|c|}{ PP telah disetujui oleh Kepala Dept. sehingga dapat dibuat PO. } \\
\hline Business Rules : & \multicolumn{2}{|c|}{ - $\quad$ PP yang tidak mendapatkan persetujuan tidak dapat ditindaklanjuti. } \\
\hline
\end{tabular}

\section{Process Design}

Dalam melakukan proses disain, akan ditampilkan Decomposition Diagram, Context Diagram, Data Flow Diagram, Data Dictionary, dan Spesifikasi Proses dari Sistem Informasi Aktiva Tetap.

\section{Decomposition Diagram}

Decomposition Diagram dalam Sistem Informasi Aktiva Tetap disesuaikan dengan kebutuhan system perusahaan tersebut. Misalkan apabila dibagi menjadi lima subsistem yang berada pada diagram level 1 dan sebelas sub subsistem yang berada pada diagram level 2. Decomposition Diagram tersebut dapat kita lihat pada Gambar 3. 


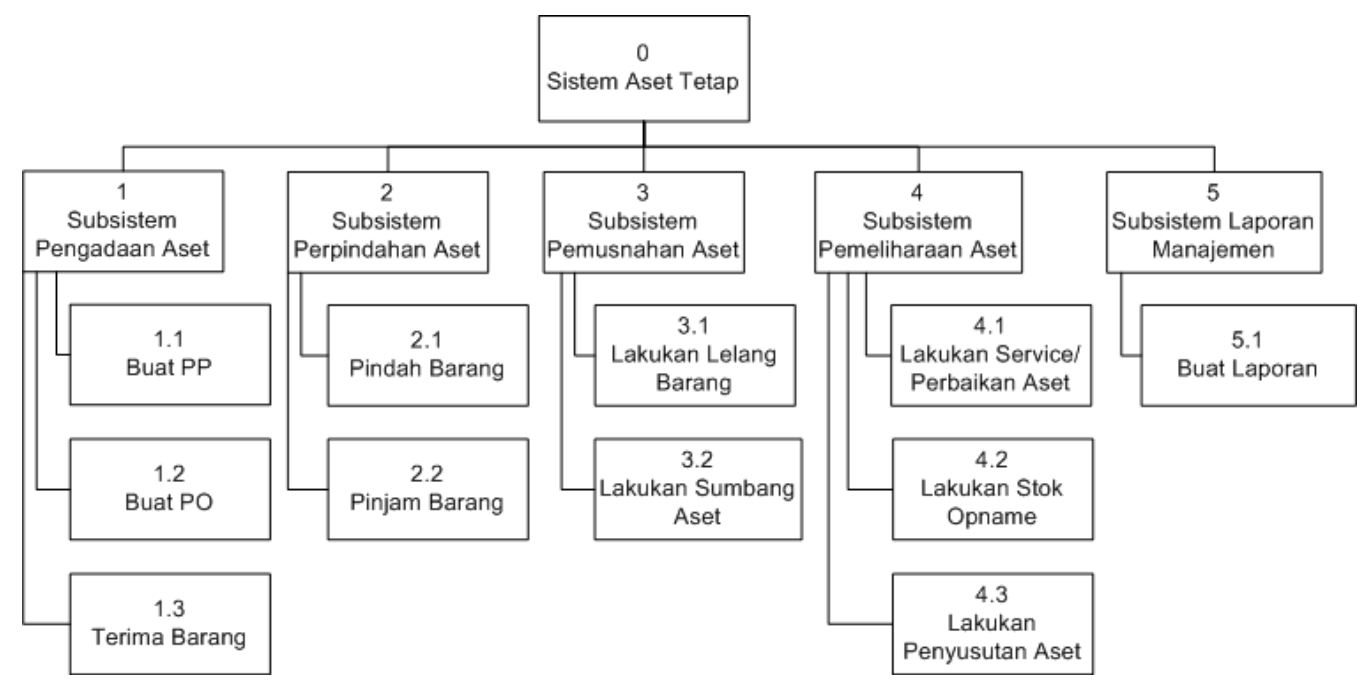

Gambar 3 Decomposition Diagram

\section{Data Flow Diagram}

Data Flow Diagramakan digambarkan menurut versi Yourdon/DeMarco. Untuk dapat dengan mudah diketahui hubungan transactional antar perusahaan dengan pihak luar, maka dapat kita lihat Context Data Flow Diagram pada Gambar 4.

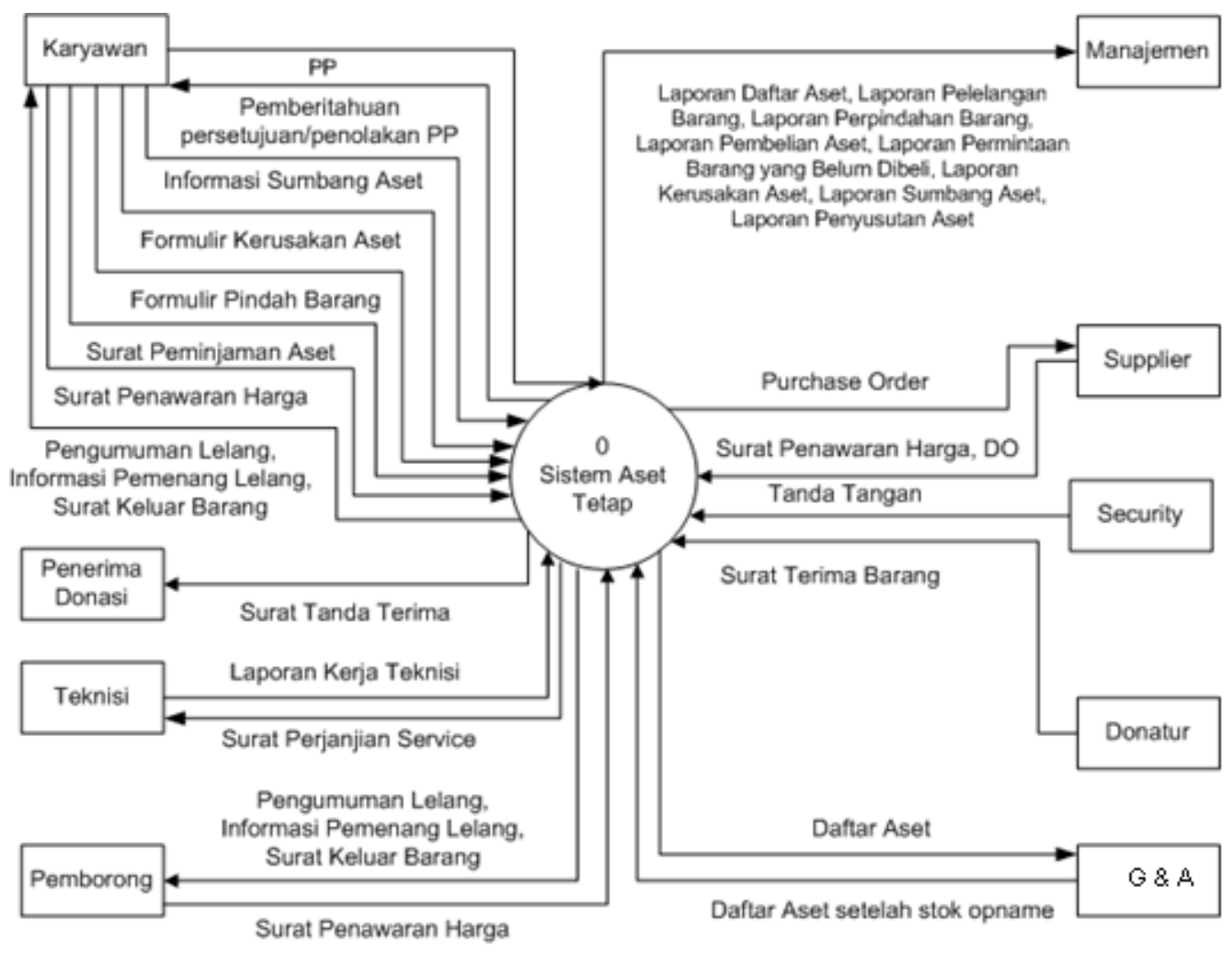

Gambar 4 ContextData Flow Diagram 


\section{Data Dictionary}

Data Dictionay menjelaskan detail untuk setiap data yang akan disimpan di database. Berikut contoh data dictionarydatastore dan data dictionary data flow pada Sistem Informasi Aktiva Tetap.

Tabel 4 Data Dictionary Datastore

\begin{tabular}{ll}
\hline Nama Data Store & Supplier \\
Deskripsi & Merupakan entity yang berisi informasi mengenai data-data supplier. \\
Struktur Data & supplier $=\{$ kodeSup + nama + alamat + kodePos + kota + person + hp + \\
& telp + fax + email + website + tglGabung + npwp + nppkp + aktif + tglInput + \\
& kodeKaryawan $\}$ \\
\hline
\end{tabular}

\section{Spesifikasi Proses}

Spesifikasi proses merupakan table yang menjelaskan dengan detail arus data seperti apa yang tersedia dalam system yang diimplementasikan tersebut. Berikut salah satu contoh spesifikasi proses yang ada pada Sistem Informasi Aktiva Tetap.

Tabel 5 Spesifikasi Proses

\begin{tabular}{|l|l|}
\hline No. Proses & 1.1 \\
\hline Nama Proses & Buat PP \\
\hline Deskripsi Proses & $\begin{array}{l}\text { Proses ini merupakan proses pembuatan Formulir Permohonan Pembelian } \\
\text { (PP) oleh karyawan unit/fakultas/bagian yang ingin mengajukan pembelian } \\
\text { aktiva. Pengisian Formulir PP ini akan update datastore PP. Formulir PP } \\
\text { akan dimintankan persetujuan ke Warek II. Hasil keputusan dari Warek II } \\
\text { akan diinformasikan oleh sistem kepada karyawan, apakah disetujui atau } \\
\text { ditolak. }\end{array}$ \\
\hline Input & Formulir PP, Data Karyawan, Data Unit, Data Aktiva \\
\hline Output & $\begin{array}{l}\text { Pemberitahuan persetujuan atau penolakan PP, Informasi PP, Informasi Detail } \\
\text { PP }\end{array}$ \\
\hline
\end{tabular}

\section{Data Dictionary Entity dalam Sistem Informasi Aktiva Tetap}

Beberapa contoh data dictionary entity dalam Sistem Informasi Aktiva, seperti pada Tabel 6.

Tabel 6 Data Dictionary Entity

$\begin{array}{ll}\text { Nama Entitas } & \text { : Supplier } \\ \text { Deskripsi } & \text { : Merupakan entity yang berisi informasi mengenai datasupplier. }\end{array}$

\begin{tabular}{llcccl}
\hline No & Nama Atribut & Tipe Data & Panjang & Key/Non Key & Keterangan \\
\hline 1 & kodeSup & Char & 5 & PK & $\begin{array}{l}\text { Berisi kode identitas } \\
\text { supplier } \\
\text { Berisi nama perusahaan } \\
\text { supplier }\end{array}$ \\
2 & nama & Varchar & 50 & NK & Berisi alamat supplier \\
3 & alamat & Varchar & 50 & NK & $\begin{array}{l}\text { Berisi nomor telepon } \\
\text { supplier }\end{array}$ \\
\hline & telp & Numeric & 10 & &
\end{tabular}


Tabel 6 Data Dictionary Entity

(lanjutan)

$\begin{array}{ll}\text { Nama Entitas } & \text { : Supplier } \\ \text { Deskripsi } & \text { : Merupakan entity yang berisi informasi mengenai datasupplier. }\end{array}$

\begin{tabular}{|c|c|c|c|c|c|}
\hline No & Nama Atribut & Tipe Data & Panjang & Key/Non Key & Keterangan \\
\hline 12 & tglGabung & Date & 8 & $\mathrm{NK}$ & $\begin{array}{l}\text { Berisi tanggal bergabungnya } \\
\text { supplier }\end{array}$ \\
\hline 13 & npwp & Numeric & 15 & NK & Berisi NPWP supplier \\
\hline 15 & aktif & Bit & 1 & NK & $\begin{array}{l}\text { Berisi ' } \mathrm{Y} \text { ' jika supplier } \\
\text { masih mensupply barang } \\
\text { atau berisi 'N' jika supplier } \\
\text { sudah tidak mensupply } \\
\text { barang }\end{array}$ \\
\hline 16 & tglInput & Date & 8 & NK & $\begin{array}{l}\text { Berisi tanggal penginputan } \\
\text { data supplier ke sistem }\end{array}$ \\
\hline 17 & kodeKaryawan & Char & 10 & FK & $\begin{array}{l}\text { Berisi kode karyawan yang } \\
\text { melakukan penginputan data } \\
\text { supplier ke sistem }\end{array}$ \\
\hline
\end{tabular}

\section{Output \& Input Design}

Pada Tahap ini dilakukan pembuatan design untuk User Interface. Salah satu output control design dalam perancangan Sistem Informasi Aktiva Tetap ini adalah adanya batasan hak akses oleh user. Tidak semua user dapat melakukan akses dalam Sistem Informasi Aktiva Tetap ini. Sebelum user masuk ke dalam sistem, sistem akan meminta user untuk memasukkan user ID dan password. Dari kata kunci yang telah dimasukkan tersbut, sistem akan memilah informasi-informasi yang boleh diakses oleh user tersebut, maka perlu disajikan Log In Window Design.

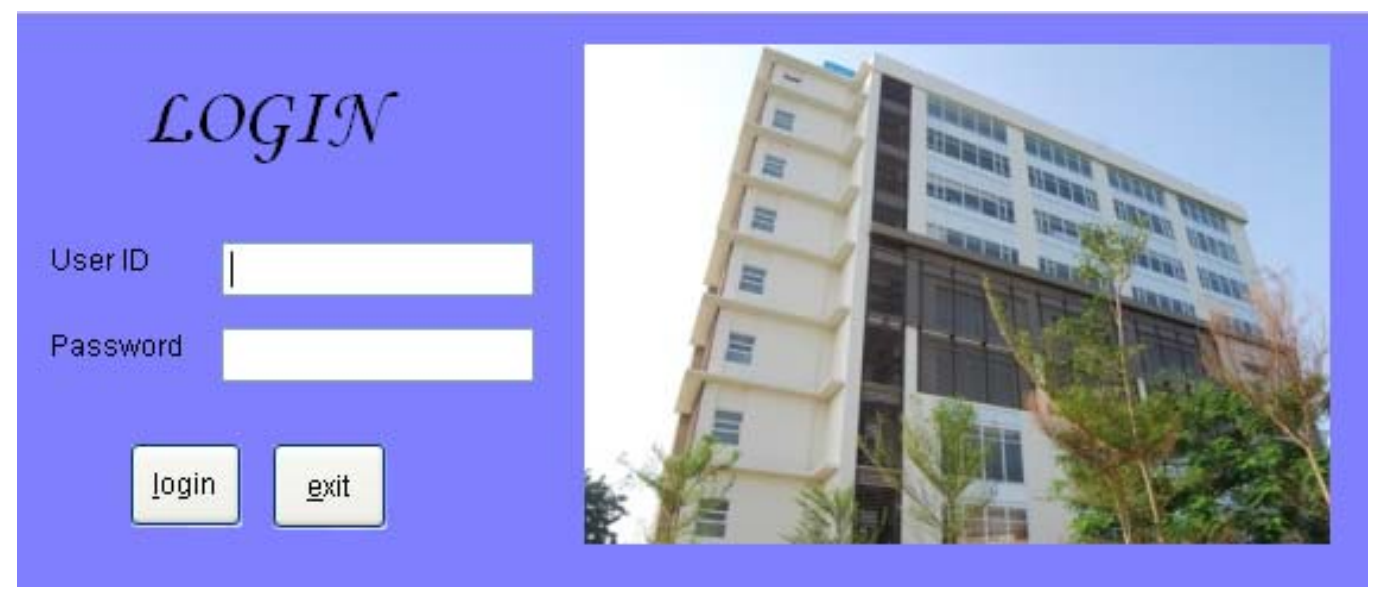

Gambar 5 Interface Login 


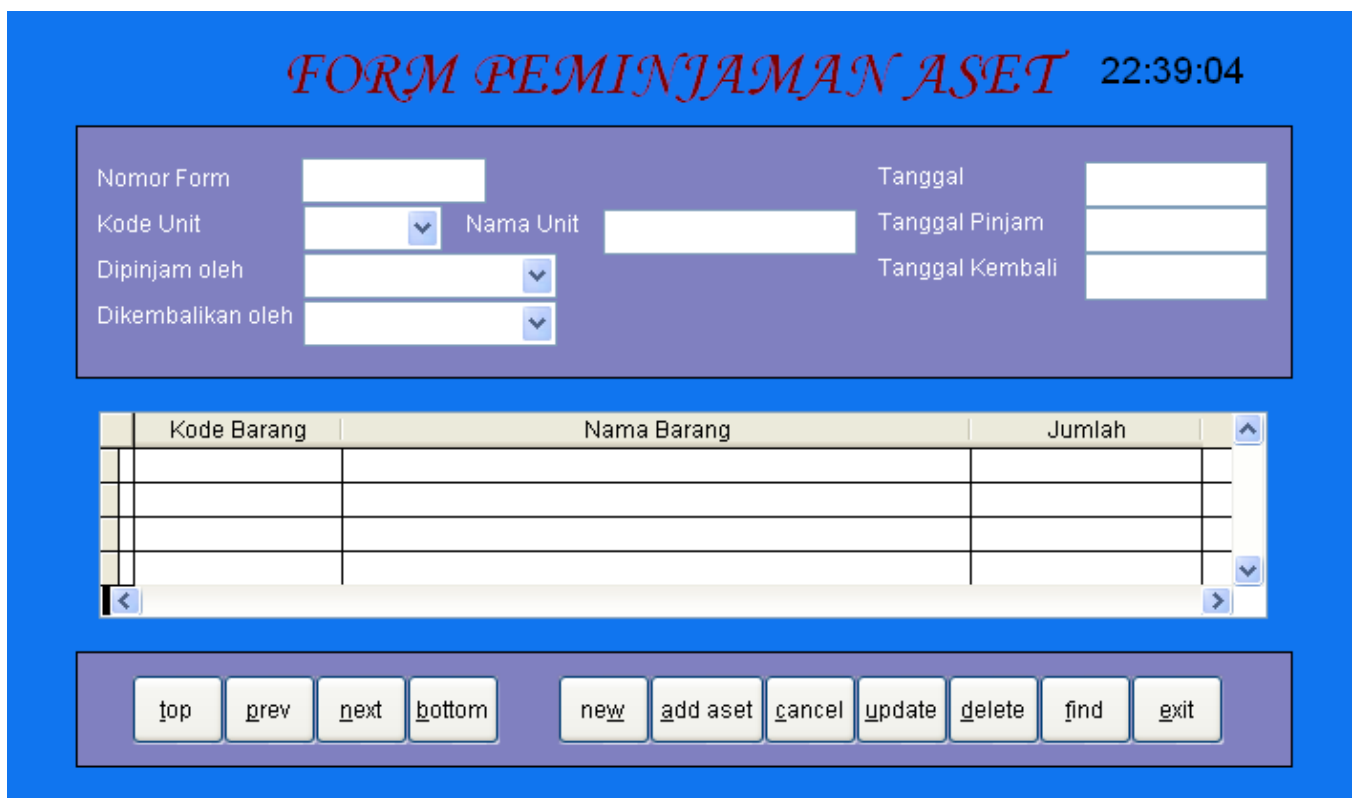

Gambar 6 Interface Peminjaman Aktiva

Tidak hanya interface output saja yang perlu dilakukan control akan tetapi interface input juga perlu dilakukan control. Berikut ini adalah beberapa hal input control design yang ada dalam Sistem Informasi Aktiva Tetap, yaitu: (1) Existence check, sistem akan melakukan pengecekan terhadap input yang dilakukukan oleh user apakah telah memenuhi keseluruhan field yang dibutuhkan oleh sistem. Jika user belum memasukkan data dengan lengkap, maka sistem akan memberikan pesan kepada user untuk melengkapi data tersebut; (2) Data type check. Sistem akan menolak apabila user melakukan kesalahan input mengenai tipe data dari field yang bersangkutan. Contohnya, field dengan tipe data numeric tidak dapat dilakukan input dengan tipe data character; (3) Checking digits. Sistem akan melakukan perhitungan jumlah digit yang dimasukkan pada field primay key. Sistem tidak akan melakukan proses selanjutnya apabila terdapat ketidakcocokan jumlah digit dari yang seharusnya. Beberapa primary key berupa nomor surat yang memungkinkan untuk sistem memberikan nomor surat secara otomatis, akan diberikan oleh sistem secara otomatis sehingga dapat meminimalkan kesalahan entry data oleh user.

\section{PENUTUP}

Sistem Informasi Aktiva Tetap yang memenuhi User Requirements dan bekerja dengan baik dapat menyediakan informasi yang tepat dan akurat yang dibutuhkan.User dapat dengan mudah mengetahui nilai perolehan dan nilai akumulasi penyusutan setiap aktiva yang sudah tidak menjadi milik perusahaan. Nilai yang berdampak pada Laporan Posisi Keuangan ini akan menghasilkan laporan yang lebih akurat dan dapat dipercaya. Selain itu, perusahaan dapat mengetahui data-data mengenai pelelangan Aktiva, sumbangan keluar, penerimaan Aktiva dari pihak luar dan masih banyak informasi lainnya seperti data donatur, data penerima donasi, data permohonan pembelian Aktiva, data barang-barang yang dibeli, data perpindahan Aktiva, data peminjaman Aktiva, data kerusakan Aktiva, laporan service Aktiva, dan laporan penyusutan Aktiva. 


\section{DAFTAR PUSTAKA}

Bentley, L. D., Whitten, J. L., \& Dittman, K. C. (2007). System Analysis \& Design for Global Enterprise (7th ed.). New York: McGraw Hill.

Bima, S. (2003). Analisis dan Perancangan Sistem Informasi Akuntansi Sistem Informasi Akuntansi pada Holding Company dari Sebuah Hotel (Studi Kasus: PT X). Jakarta.

Dennis, Alan, Barbara Haley Wixom, David Tegarden. (2010). System Analysis and Design with UML An Object-Oriented Approach $3^{\text {rd }}$ Edition. John Wiley \& Sons, Inc

Frederica, D. (2010). Analisis dan perancangan sistem informasi Aktiva tetap studi kasus pada Universitas X (Studi Kasus: Universitas X). Jakarta.

Romney, M., \& Steinbart, P. (2009). Accounting Information System (11th ed.). Pearson Education.

\section{RIWAYAT PENULIS}

Eka Novianti lahir di kotaTasikmalaya pada 11 November 1979. Penulis menamatkan pendidikan S2 di Program Magister Akuntansi UI dalam bidang Akuntansi pada 2008. Saat ini bekerja sebagai pengajar di Binus University. 